\title{
BIBECHANA
}

A Multidisciplinary Journal of Science, Technology and Mathematics ISSN 2091-0762 (Print), 2382-5340 (Online)

Journal homepage: http://nepjol.info/index.php/BIBECHANA

Publisher: Research Council of Science and Technology, Biratnagar, Nepal

\section{Mechanical and thermal properties of triblock copolymer modified epoxy resins}

\author{
Shankar P. Khatiwada ${ }^{1,2}$, Sabu Thomas ${ }^{3}$, Jean Marc Saiter ${ }^{4}$, Ralf Lach ${ }^{5}$, Rameshwar Adhikari ${ }^{1,6}$ \\ ${ }^{1}$ Research Center for Applied Science and Technology, Tribhuvan University, Kirtipur, Kathmandu, Nepal \\ ${ }^{2}$ Nepal Polymer Institute (NPI), P. O. Box 24411, Kathmandu, Nepal \\ ${ }^{3}$ School of Chemical Sciences, Mahatma Gandhi University, Kottayam, Kerala, India \\ ${ }^{4}$ Université de Normandie Rouen Laboratoire SMS Faculté des Sciences and Onyx Developpment, \\ Groupe-Nutriset, Rouen, France \\ ${ }^{5}$ Polymer Service GmbH Merseburg (PSM), Merseburg, Germany \\ ${ }^{6}$ Central Department of Chemistry, Tribhuvan University, Kirtipur, Katmandu, Nepal \\ "Email: nepalpolymer@yahoo.com
}

Article history: Accepted 06 November, 2018

DOI: http://dx.doi.org/10.3126/bibechana.v16i0.21651

This work is licensed under the Creative Commons CC BY-NC License.

https://creativecommons.org/licenses/by-nc/4.0/

\section{(i) (8)}

\begin{abstract}
We investigate the ways of improving thermal and mechanical properties of diglycidyl ether of bisphenol-A (DGEBA) based thermoset resin using diaminodiphenylsulphone (DDS) as hardener and using epoxidized polystyrene/polybutadiene-based triblock copolymers as modifier. The epoxidation was performed. The targeted chemical modification using meta-chloroperoxybenzoic acid ( $m$-CPBA) of the copolymer was performed whereby the epoxidation of the butadiene chains mainly took place at 1,4 linkages. The modification copolymer was found to contribute in enhancing the mechanical performance of the blends with epoxy resin. The results indicated the formation of nanostructured morphology in the blends attributable to their enhanced impact strength.
\end{abstract}

Keywords: Block copolymers, Epoxy resins, Toughness, Mechanical properties.

\section{Introduction}

Epoxy thermoset have found uses in diverse applications ranging from adhesives to bulk components, widely used in industry as protective coatings and for structural applications, such as laminates and composites, tooling, molding, casting and others [1]. Epoxy resins are having at least two epoxy groups which react to form a highly crosslinked networks that are stiff, chemically and environmentally resistant, have good mechanical and thermal properties for high temperature applications as well as outstanding adhesion to various substrates, low shrinkage. However, these benefits are limited by the fact that the crosslinked resins are typically brittle possessing relatively poor fracture toughness and ductility [2]. 
To amplify the area of commercial applications available to epoxy materials, strategy for improving the fracture toughness with little or no loss of the desired stiffness and thermal stability must be developed. For this purpose, a common toughening mechanism such as an addition of the phase separating additives to the epoxy system can be followed. For example, the addition of thermoplastic elastomer has been shown to offer effective toughening of epoxy resin materials [3]. However, the addition of more rubber into the epoxy resin can give rise to processing difficulties and the drop-in glass transition temperature $\left(\mathrm{T}_{\mathrm{g}}\right)$ and elastic modulus of the thermoset [4]. Thus, the use of block copolymer as toughening agent has been explored quite comprehensibly [5-10]. In most cases, the formation of nanostructures was reported by incorporating AB-type diblock copolymers into thermosets [5-13]. Also, the ordered nanostructures formed by $\mathrm{ABC}$ triblock copolymers and hydrogenated systems were investigated [14-18]. However, the structural effect of block copolymers on the formation of nanostructures in thermosets was occasionally investigated. This work is aimed at the study of thermal and mechanical properties of the epoxy resins modified by styrene-rich styrenic triblock copolymer having linear asymmetric architectures.

\section{Experimental Section}

\subsection{Materials}

The diglycidyl ether of bisphenol-A (DGEBA) resin was supplied by Araldite LY556 Huntsman and had an average epoxy equivalent of $186 \mathrm{~g}$ /equiv. The curing agent used was diaminodiphenylsulphone (DDS) supplied by Fluka. Other chemicals like meta-chloroperoxybenzoic acid (m-CPBA), sodium bicarbonate $\left(\mathrm{NaHCO}_{3}\right)$ and sodium sulphate $\left(\mathrm{Na}_{2} \mathrm{SO}_{4}\right)$ were purchased from the local market and used without further purification. The chemical structure of DGEBA and DDS are shown in Fig. 1.

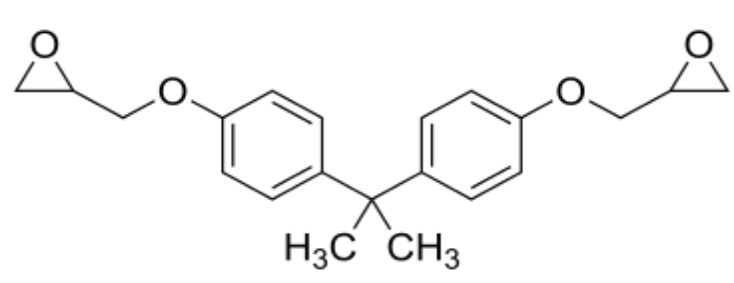

Diglycidyl ether of bisphenol-A (DGEBA)<smiles>Nc1cccc(S(=O)(=O)c2cccc(N)c2)c1</smiles>

Diaminodiphenylsulphone (DDS)

Fig. 1: Chemical structures of diglycidyl ether of bisphenol-A (DGEBA) (left) and 4,4 diaminodiphenylmethane (DDM) (right); the components used to prepare epoxy resin systems.

The polystyrene-polybutadiene-based triblock copolymer (which has been named as LN3 in this and previous publications) was supplied by BASF SE, Ludwigshafen, Germany. The triblock copolymer has $74 \%$ by volume of styrene, number average molecular weight (Mn) $127 \mathrm{~kg} / \mathrm{mol}$ and polydispersity index (Mw/Mn, where $\mathrm{Mw}$ is the weight average molecular weight) of 1.1. More studies on this block copolymer can be found elsewhere [19].

\subsection{Epoxidation of block copolymer}

The epoxidation of the styrene/butadiene-based triblock copolymer was accomplished following the standard method by using $m$-CPBA [20-21]. In a typical experiment, $10 \mathrm{~g}$ of LN3 and $200 \mathrm{~mL}$ of dichloromethane were poured into a three-necked round bottomed flask and stirred gently by magnetic stirrer until the polymer dissolved. To achieve a degree of epoxidation (DOE) of $80 \mathrm{~mol} \%$; 
calculated amount of $m$-CPBA were charged to the polymer solution. The chemical modification reaction is presented in schematically in Fig. 2.

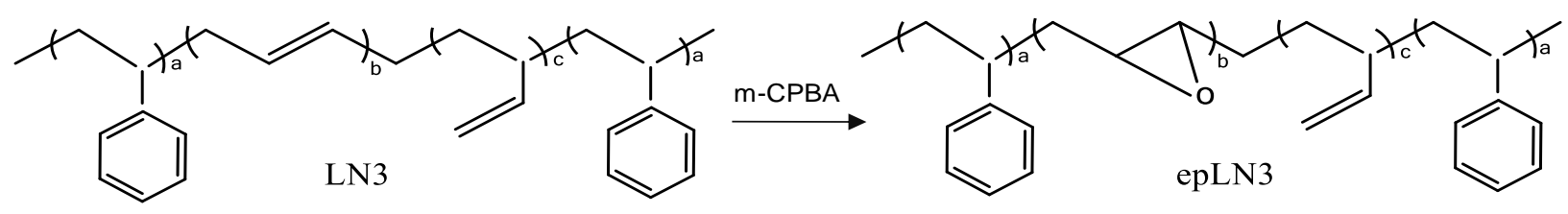

Fig. 2: Schematic of chemical reaction involved in epoxidation of the block copolymer.

The mixture was then vigorously agitated for two hours under dry $\mathrm{N}_{2}$ gas atmosphere at $0{ }^{\circ} \mathrm{C}$. After the reaction was complete, the polymer solution was filtered. The excess $\mathrm{m}-\mathrm{CPBA}$ was removed by extracting with a saturated aqueous $\mathrm{NaHCO}_{3}$ solution and the mixture was further dried by the $\mathrm{Na} 2 \mathrm{SO} 4$ solution. The final polymer solution was recovered using a separating funnel and a vacuum suction pump. The solvent was evaporated to recover the solid residue which was vacuum dried at 23 ${ }^{\circ} \mathrm{C}$. The name epLN3 is used for the epoxidized sample.

\subsection{Synthesis of blends with epoxy resin}

Pure epoxy thermoset was prepared by the reaction of stoichiometric amount of DGEBA with DDS (EP: DDS= 3:1). The mixture was pre-cured at $180^{\circ} \mathrm{C}$ for 3 hours followed by post curing at $200^{\circ} \mathrm{C}$ for 2 hours. Epoxidized epLN3 was dissolved in dichloromethane and blended with 5, 10 and 15 by weight $\%$ of the epLN3. The mixture was heated up to $100^{\circ} \mathrm{C}$ to completely evaporate the solvent. Then, the temperature was increased to $180^{\circ} \mathrm{C}$ and stoichiometric amount of DDS hardener was added.

The resultant mixture was stirred until the complete dissolution of the DDS leading to the homogenous mixture. As in the case of pure thermoset resin, the mixture containing epLN3 was cured. Each cured blend was cooled gradually down to room temperature. Thus, the prepared blends were named as EP, EP/epLN3-5, EP/epLN3-10 and EP/epLN3-15 for those blends containing 0, 5, 10 and 15 wt.-\% of epLN3.

\subsection{Experimental techniques}

Fourier transform infrared (FTIR) spectroscopy was used to record the infrared spectra of the polymers using Jasco FTIR 615 instrument using ATR transmission mode in the wavenumber range $4000 \mathrm{~cm}-1$ to $600 \mathrm{~cm}-1$.

The impact strength of the blends was measured using Izod impact tester according to ASTM D256 method. The sample dimensions were $100 \mathrm{~mm} \times 12 \mathrm{~mm} \times 3 \mathrm{~mm}$ and a notch of $1.5 \mathrm{~mm}$ in depth was introduced in to each specimen at a distance of $20 \mathrm{~mm}$ from one end. The hammer speed was $2.9 \mathrm{~m} / \mathrm{s}$ with working capacity $4 \mathrm{~J}$. At least five successive measurements were performed for each sample and the results were averaged.

Scanning electron microscopy (SEM) was used to study the morphologies of cryo-fractured surfaces of the samples. The specimens were sputter coated with a thin layer of platinum $(\sim 3 \mathrm{~nm})$ in order to avoid surface charging.

Thermogravimetric analysis (TGA) was performed by of thermogravimetric analysis using Netzsch TGA 209 Balance under $\mathrm{N}_{2}$ atmosphere from $20^{\circ} \mathrm{C}$ to $700^{\circ} \mathrm{C}$ at a heating rate of $10^{\circ} \mathrm{C} / \mathrm{min}$. The pressure of 1 bar was maintained with flow rate $15 \mathrm{~mL} / \mathrm{min}$ in this analysis. 
Dynamic mechanical analysis (DMA) measurements was carried out on specimens with dimensions of $30 \mathrm{~mm} \times 10 \mathrm{~mm} \times 1 \mathrm{~mm}$ using an ARES G2 Rheometer in torsion mode to characterize the glass transition behavior of the sample using standard oscillatory temperature sweeps between $0^{\circ} \mathrm{C}$ and 250 ${ }^{\circ} \mathrm{C}$ at a frequency of $1 \mathrm{rad} / \mathrm{s}$.

\section{Results and Discussion}

\subsection{Structural characterization}

The FTIR spectra of the virgin LN3 and its epoxidized version (epLN3) are presented in Fig. 3.

The peaks located at $910 \mathrm{~cm}-1$ and $965 \mathrm{~cm}-1$ for the virgin $\mathrm{LN} 3$ correspond to $\mathrm{C}-\mathrm{H}$ bending vibration of vinyl side chains $(-\mathrm{CH}=\mathrm{CH} 2-)$ and trans 1,4 polybutadiene chains (- $\mathrm{CH} 2-\mathrm{CH}=\mathrm{CH}-\mathrm{CH} 2-)$, respectively. The epoxidation of the 1,4 butadiene parts of the block copolymer is confirmed by the appearance of new peaks located around $890 \mathrm{~cm}-1$ and $810 \mathrm{~cm}-1$ for trans- and cis- 1,4 epoxidized copolymer respectively. After epoxidation, the peak corresponding to 1,4 butadiene decreases but that corresponding to 1,2 butadiene remains unchanged implying that the chemical modification of the butadiene chains mainly takes place at 1,4 linkages. Thus, on the basis of the spectroscopic results, the targeted chemical modification of the copolymer can be confirmed. So far, the extent of the chemical modification cannot be ascertained by the spectroscopic methods. These results are in consistence with the previous works reported in similar system [22].

\subsection{Mechanical behavior}

The notched Izod impact strength of pure epoxy thermoset (EP) compared with epoxy blends with 5, 10 and 15 wt.-\% of epLN3 are presented in Fig. 4. One can see that the value of impact strength increases insignificantly for the blend containing $5 \mathrm{wt} .-\%$ of epLN3. In case of blends with the higher amount of epLN3, however, the impact strength increases. Among all the blends, EP/epLN3-15 shows much better impact strength $\left(6 \mathrm{~kJ} / \mathrm{m}^{2}\right)$ compared to pure epoxy thermoset $\left(3.7 \mathrm{~kJ} / \mathrm{m}^{2}\right)$. The reason behind this observation is the proper miscibility of the epLN3 with the EP and leading to larger plastic deformation of the material dissipation higher amount of energy delaying the crack propagation [23]. In summary, the epLN3 contributes to quite significantly enhance the mechanical performance of the blends. The results thus give indication of the evolution of morphologies in the blends which might be responsible for enhancing their observed impact strength at higher epLN3 contents. The exact morphologies must be, however, further investigated for precise structure-properties correlations.

SEM images of the cured samples after fracture toughness test are shown in Fig. 5. The fracture surface of the single-phase neat epoxy resin (Fig. 5a) appears typically, smooth with the cracks rippled freely and orienting in the loading direction representative of brittle failure and resulting in poor resistance to crack initiation and uninterrupted crack propagation [23]. Owing to the better compatibility of epLN3 in the EP matrix chain, the dispersed phase could be epLN3 were distributed throughout the thermoset material. Thus, the fractured surface has been changed significantly at higher loading of epLN3. As a result, an irregular fracture patch with stretched fibrils appearing stress whitened edges were observed in case of blend containing 5 wt.- $\%$ of epLN3 as shown in Fig. 5b.

The result provided an evidence of plastic deformation. Numerous fibrillar fracture patches were observed in the blends containing large amount of epLN3.

\subsection{Thermal behaviors}

Thermal properties of the epoxy-based materials analyzed by thermogravimetric analysis (TGA), are presented in Fig. 6 and 7 as well in Table 1. Typical TGA curves of mass loss as a function of temperature of EP is compared with that of blends are presented in Fig. 6. At the first glance, similar 
TGA curves are shown by all materials. However, some changes can observe if the curves are carefully analyzed. The weight loss of the materials containing different amount of epLN3 occurs mainly between $340{ }^{\circ} \mathrm{C}$ and $500{ }^{\circ} \mathrm{C}$, and the temperatures of initial degradation for the blends with 5 $\%$ mass loss (Td5) are apparently higher than that of the pure thermoset resin.

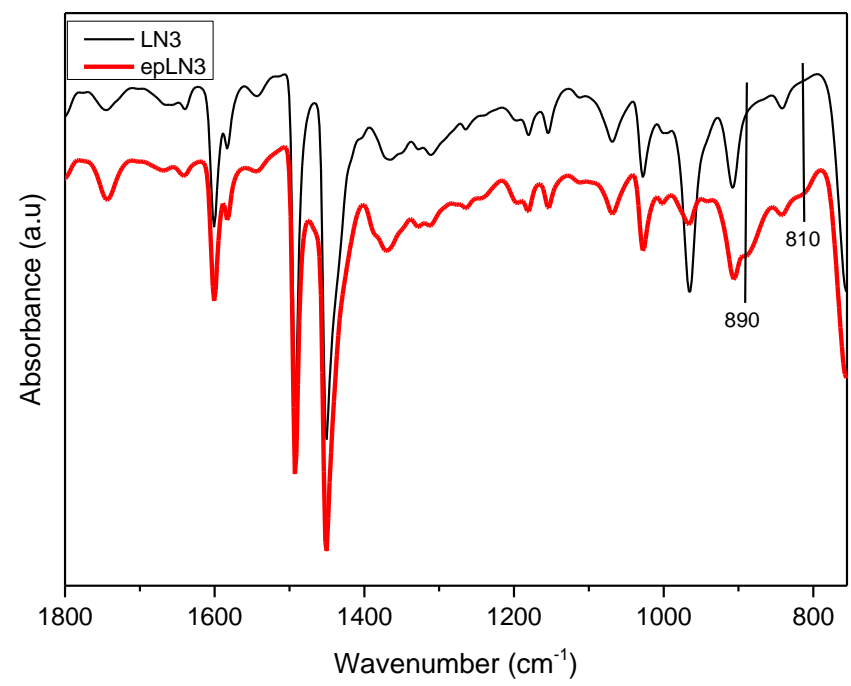

Fig. 3: FTIR spectra of LN3 and epLN3.
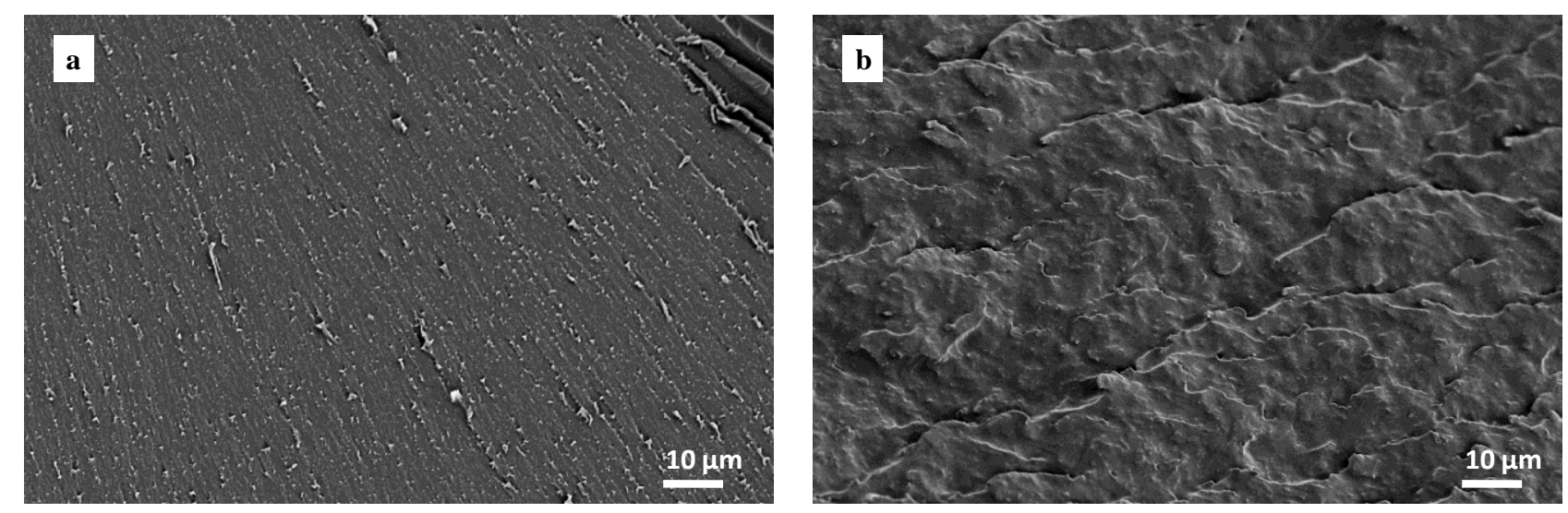

Fig. 5: SEM image showing the fracture surface morphology of neat epoxy resin (EP) (a) and EP/epLN3-10.

The first derivative peak temperature (not shown here) indicates the point of the greatest rate of mass loss during degradation. Here all materials show same first derivative peak at $418{ }^{\circ} \mathrm{C}$. That indicates the all materials have usually similar thermal behavior. The char yield of EP thermoset at $600{ }^{\circ} \mathrm{C}$ is $17.6 \%$ of original mass while the yield slightly increases up to $18.9 \%$ after blending with increasing amount of epLN3. This might be because of the contribution of different amount of epLN3 making the stable network by some interaction. 
In order to analyze the activation energy of thermal degradation during the curing process, detailed analysis of the TGA data obtaining through temperature scanning procedures was carried out using kinetic model. For degradation process, the rate of reaction can be expressed as a function of curing degree [24]. The rate constant of the curing reaction is generally expressed by Arrhenius equation as in Eqn. 1.

$$
\frac{\mathrm{d} \alpha}{\mathrm{dt}}=\mathrm{F}(\alpha) \cdot \mathrm{K}(\mathrm{T})=\mathrm{A} \cdot \mathrm{e}^{-\frac{\mathrm{Ea}}{\mathrm{RT}} \mathrm{F}} \cdot(\alpha)
$$

where $\mathrm{A}$ is a pre-exponential factor (1/min), Ea is the apparent activation energy in $\mathrm{J} / \mathrm{mol}, \mathrm{T}$ is the absolute temperature $(\mathrm{K})$ and $\mathrm{R}$ is the gas constant $(8.3136 \mathrm{~J} / \mathrm{mol} \mathrm{K}-1)$. For each sample, the sudden mass loss was observed and the Ea values can thus be calculated from the slope of the linear part of $\mathrm{ln}$ (d $\alpha / \mathrm{dt})$ versus 1/T curves as shown in Fig. 7.

In similar manner the Ea values for the blends were calculated from the slop of the curves in Fig. 7 the values of Ea was calculate calculated (see Table 1).

Table 1: Activation energy obtained from slope of $\ln (\mathrm{d} \alpha / \mathrm{dt})$ versus $1 / \mathrm{T}$ curves.

\begin{tabular}{ll}
\hline Sample & Activation energy $\left(\mathrm{E}_{\mathrm{a}}\right) \mathrm{kJ} / \mathrm{mol}$ \\
\hline EP & 318 \\
EP/epLN3-5 & 350 \\
EP/epLN3-10 & 354 \\
EP/epLN3-15 & 446 \\
\hline
\end{tabular}

For the given temperature range, the Ea value of neat epoxy resin is found to be $318 \mathrm{~kJ} / \mathrm{mol}$. Similarly, the Ea values of blends were found to be in increasing order with increase in epLN3 composition. The reason behind this phenomenon needs further investigations.

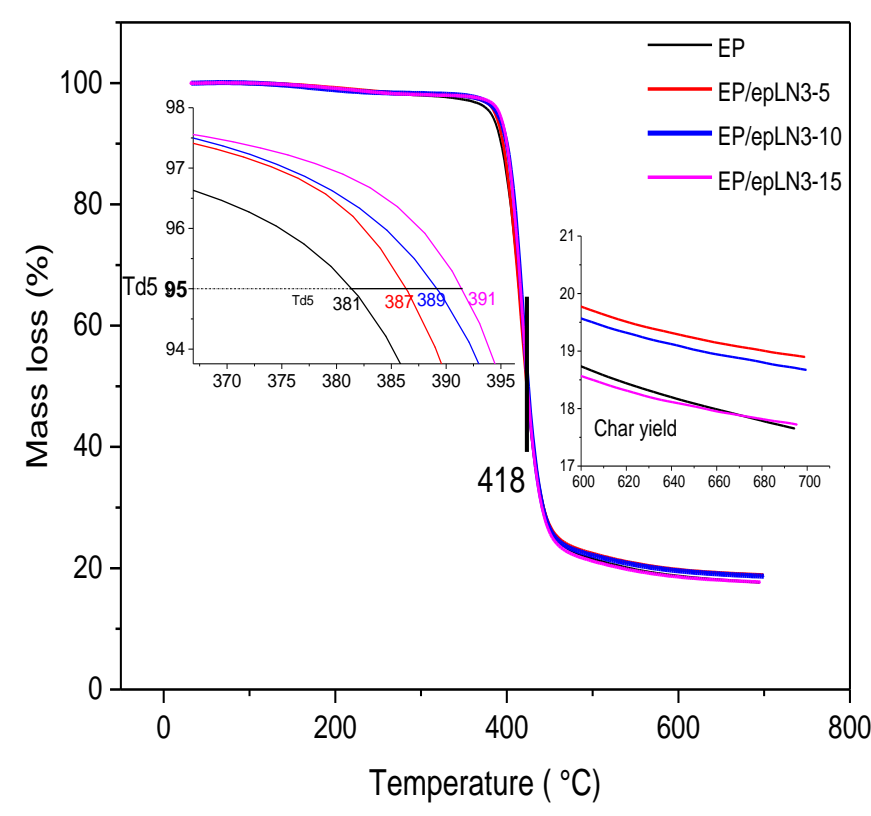

Fig. 6: TGA curves for neat EP compared with EP/epLN3 blends modified with different amount of epLN3.

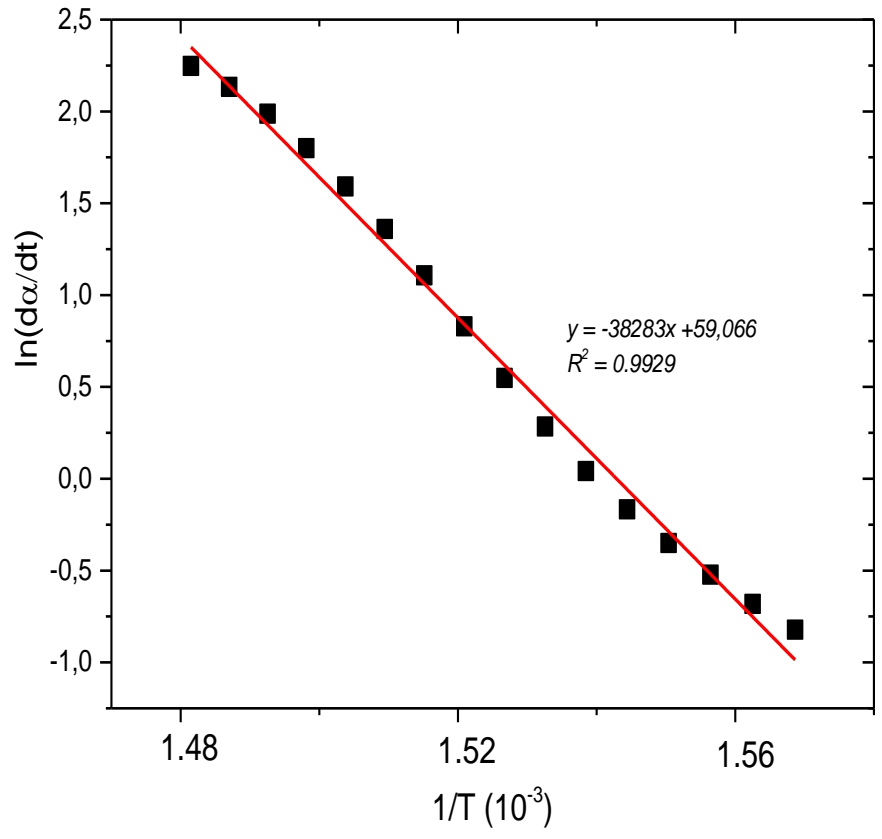

Fig.7: $\ln (\mathrm{da} / \mathrm{dt})$ versus $1 / \mathrm{T}$ plots for calculation of activation energy of neat epoxy resin (EP). 


\section{Conclusions}

The results presented in this paper can be summarized as follows:

(a) On the basis of the spectroscopic results, the targeted chemical modification of the copolymer can be confirmed. It was further observed that the chemical modification of the butadiene chains mainly took place at 1,4 linkages.

(b) The modified block copolymer contributes to quite significantly enhance the mechanical performance of the blends with epoxy resin. The results thus give an indication of the formation of nanostructured morphology in the blends which might be responsible for enhancing their impact strength at higher epLN3 content.

(c) Based on the thermogravimetric analyses, the enhanced stability of the blends can be correlated with the formation of nanostructured morphology of the blends.

\section{Acknowledgements}

SPK thanks German Academic Exchange Service (DAAD) ((57129430) for providing the Ph.D. scholarship and further acknowledges Prof. Gert Heinrich (IPF, Dresden, Germany) for experimental support and fruitful discussions.

\section{References}

[1] L.V. McAdams, J.A. Gannon, In: High Performance Polymer and Composites, J.I. Kroschwitz, ed., John Wiley and Sons, Hoboken (1991) 258-318.

[2] G. Tesoro, In: Epoxy Resins: Chemistry and Technology, C.A. May, ed., Marcel Dekker, New York, 26 (1988) 539-539. doi.org/10.1002/pol.1988.140261212.

[3] H.J. Sue, E.I. Garcia-Meitin, D.M. Pickelman, In: Polymer Toughening, C.B. Arends, ed., Marcel Dekker, New York (1996) 131-174.

[4] L.H. Sperling, Introduction to Physical Polymer Science, L.H. Sperling, ed., Wiley, New York. 1996 doi.org/10.1002/pola.1993.080310435.

[5] M.A. Hillmyer, P.M. Lipic, D.A. Hajduk, K. Almdal, F.S. Bates. Self-assembly and polymerization of epoxy resin-amphiphilic block copolymer nanocomposites, J. Am. Chem. Soc. 119 (1997) 2749-2750. doi.org/10.1021/ja963622m.

[6] P.M. Lipic, F.S. Bates, M.A. Hillmyer, Nanostructured thermosets from self-assembled amphiphilic block copolymer/epoxy resin mixtures, J. Am .Chem. Soc. 120 (1998) 8963-8970. doi.org/10.1021/ja981544s.

[7] J. Wu, Y.S. Thio, F.S. Bates, Structure and properties of PBO-PEO diblock copolymer modified epoxy, J. Polym. Sci. Part B Polym. Phys. 43 (2005) 1950-1965. doi.org/10.1002/polb.20488.

[8] Q. Guo, J..M.E. Dean, R.B. Grubbs, F.S. Bates, Block copolymer modified novolac epoxy resin, J. Polym. Sci. Part B: Polym. Phys. 41 (2003) 1994-2003.doi.org/10.1002/polb.10554.

[9] J. Mijovic, M. Shen, J.W. Sy, Mondragon I., Dynamics and morphology in nanostructured thermoset network/block copolymer blends during network formation, Macromolecules 33 (2000) 5235-5244. doi.org/10.1021/ma991894e.

[10] Q. Guo, R. Thomann, W. Gronski, Nanostructures, semicrytalline morphology, and nanoscale confinement effect on the crystallization kinetics in self-organized block copolymer/thermoset blends, Macromolecules 36 (2003) 3635-3645. doi.org/10.1021/ma0340154.

[11] S. Ritzenthaler, F. Court, E. Girard-Reydet, L. Leibler, J.P. Pascault, ABC triblock copolymers/epoxydiamine blends, 1 . Keys to achieve nanostructured thermosets, Macromolecules 35 (2002) 6245-6254. doi.org/10.1021/ma0121868.

[12] S. Ritzenthaler, F. Court, E. Girard-Reydet, L. Leibler, J.P. Pascault, ABC triblock copolymers/epoxydiamine blends, 2, Parameters controlling the morphologies and properties, Macromolecules 36 (2003) 118-126. doi.org/10.1021/ma0211075. 
Shankar P. Khatiwada et al./ BIBECHANA 16 (2019) 196-203: RCOST p.203 (Online Publication: Dec., 2018)

[13] H. Kosonen, J. Ruokolainen, P. Nyholm, O. Ikkala, Self-organized thermosets: Blends of hexamethyltetramine cured novolac with poly(2-vinylpyridine)-block-poly(isoprene), Macromolecules 34(2001) 3046-3049. doi.org/10.1021/ma001559m

[14] V. Rebizant, V. Abetz, T. Tournihac, F. Court, L. Leibler, Reactive tetrablock copolymers containing glycidyl methacrylate, synthesis and morphology control in epoxy-amine networks, Macromolecules 36 (2003) 9889--9896. doi.org/10.1021/ma0347565.

[15] V. Rebizant, A.S. Venet, F. Tournillhac, E. Girard-Reydet, C. Navarro, J.P. Pascault, Chemistry and mechanical properties of epoxy-based thermosets reinforced by reactive and nonreactive SBMX block copolymers, Macromolecules 37 (2004) 8017-8027. doi.org/10.1021/ma0490754.

[16] I.A. Zucchi, M.J. Galante, R.J.J. Williams. Comparison of morphologies and mechanical properties of crosslinked epoxies modified by polystyrene and poly(methyl methacrylate) or by the corresponding block copolymer polystyrene-b-poly(methyl methacrylate), Polymer 46 (2005) 2603-2609. doi.org/10.1016/j.polymer.2005.02.012.

[17] E. Serrano, A. Tercjak, G. Kortaberria, J.A. Pomposo, D. Mecerreyes, N.E. Zafeiropoulos, Nanostructured thermosetting systems by modification with epoxidized styrene-butadiene star block copolymers, Effect of epoxidation degree, Macromolecules 39 (2006) 2254-2261. doi.org/10.1021/ma0515477.

[18] E. Serrano, M. Larran aga, P.M. Remiro, I. Mondragon, Nanostructured thermosetting systems from epoxidized styrene butadiene block copolymers, Macromol Rapid Commun. 26 (2005) 982-985. doi.org/10.1002/marc.200500131.

[19] R. Adhikari, T.H. An, M. Buschnakowski, G.H. Michler, K. Knoll, Asymmetric PS-block-(PS-co-PB)block-PS block copolymers: morphology formation and deformation behavior, New Journal of Physics 6 (2004) 1-20. doi.org/10.1088/1367-2630/6/1/028.

[20] S.P. Khatiwada, C.S. Chandran, R. Lach, M. Liebscher, J.M. Saiter, S. Thomas, G. Heinrich, R. Adhikari, Morphology and mechanical properties of star block copolymer modified epoxy resin blends, Mater. Today Proc. 4 (2017) 5734-5742. doi.org/10.1016/j.matpr.2017.06.038.

[21] C. Ocando, A. Tercjak, M.D. Martion, J.A. Ramos, M. Campo, I. Mondragon, Morphology development in thermosetting mixtures through the variation on chemical functionalization degree of poly(styrene-bbutadiene) diblock copolymer modifiers, Thermomechanical properties, Macromolecules 42 (2009) 6215-6224. doi.org/10.1021/ma900885b.

[22] R. Pandit, G. H Michler, R. Lach, W. Grellmann, J. M. Saiter, A. Berkessel, R. Adhikari, Epoxidation of styrene/butadiene star block copolymer by different methods and characterization of the blends with epoxy resin, Macromol. Symp. 341 (2014) 67-74. doi.org/10.1002/masy.201400001.

[23] S.Yamini, R.J. Young, Stability of crack propagation in epoxy resins, Polymer 18 (1977) 1075-1080. doi.org/10.1016/0032-3861(77)90016-7.

[24] A. Arbelaiz, B. Fernandez, J.A. Ramos, I. Mondragon, Thermal and crystallization studies of short flax fibre reinforced polypropylene matrix composites: Effect of treatments, Thermochimica Acta 440 (2006) 111-121. doi.org/10.1016/j.tca.2005.10.016. 